\title{
A parametric method to model 3D displacements around faults with volumetric vector fields ${ }^{\text {th }}$
}

\author{
Gautier Laurent ${ }^{\mathrm{a}, \mathrm{b}, *}$, Guillaume Caumon ${ }^{\mathrm{a}, \mathrm{b}}$, Antoine Bouziat ${ }^{\mathrm{a}, \mathrm{b}, 1}$, Mark Jessell ${ }^{\mathrm{c}}$, Gautier Laurent $^{\mathrm{a}, \mathrm{b}, *}$, \\ Guillaume Caumon ${ }^{\mathrm{a}, \mathrm{b}}$, Antoine Bouziat ${ }^{\mathrm{a}, \mathrm{b}, 1}$, Mark Jessell $^{\mathrm{c}}$ \\ ${ }^{a}$ Université de Lorraine, CRPG UPR 2300, Vandoeuvre-lès-Nancy, 54501, France \\ ${ }^{b}$ CNRS, CRPG, UPR 2300, Vandoeuvre-lès-Nancy, 54501, France \\ ${ }^{c} I R D$, UR 234, GET, OMP, Université Toulouse III, 14 Avenue Edouard Belin, 31400 Toulouse, FRANCE
}

\begin{abstract}
This paper presents a 3D parametric fault representation for modeling the displacement field associated with faults in accordance with their geometry. The displacements are modeled in a canonical fault space where the near-field displacement is defined by a small set of parameters consisting of the maximum displacement amplitude and the profiles of attenuation in the surrounding space. The particular geometry and the orientation of the slip of each fault is then taken into account by mapping the actual fault onto its canonical representation. This mapping is obtained with the help of a curvilinear frame aligned both on the fault surface and slip direction.

This formulation helps us to include more geological concepts in quantitative subsurface models during 3D structural modeling tasks. Its applicability is demonstrated in the framework of forward modeling and stochastic sequential fault simulations, and the results of our model are compared to observations of natural objects described in the literature.
\end{abstract}

Keywords: structural modeling, fault, parameterization, kinematics, time integration

\section{Introduction}

Faults dramatically impact fluid flow, mineralization, facies localization and the geometry and connectivity of rock units. In subsurface modeling, an accurate description of faults is therefore paramount in maximizing a model's predictive capabilities. In general, uncertainties associated with

${ }^{\star}$ Published in Tectonophysics, Vol 590 (Jan 2013), pp 8393 doi:10.1016/j.tecto.2013.01.015

*Corresponding author: Université de Lorraine, CRPG UPR 2300, Vandoeuvre-lès-Nancy, 54501, France. Tel.: +333835964 42. Fax: +33383586460. E-mail address: laurent@gocad.org (G. Laurent)

Email addresses: laurent@gocad.org (Gautier Laurent), caumon@gocad.org (Guillaume Caumon), antoine.bouziat@cggveritas.com (Antoine Bouziat), mark.jessell@get.obs-mip.fr (Mark Jessell),

laurent@gocad.org (Gautier Laurent), caumon@gocad.org (Guillaume Caumon), antoine.bouziat@cggveritas.com (Antoine Bouziat), mark.jessell@get.obs-mip.fr (Mark Jessell)

${ }^{1}$ Presently at Hampson-Russell Software \& Services - CGGVeritas, Crawley, United-Kingdom. faults are significant, particularly concerning their connectivity and the displacement of surrounding rocks. These two aspects are intimately related to the kinematics and mechanics of the fault. Unfortunately, the compatibility with deformation history, tectonics, kinematics and mechanical concepts is generally secondary in current processes of quantitative 3D modeling, the main objective being to fit the data while honoring geometrical constraints such as minimizing the curvature of the structures (Caumon et al. 2009).

Typical geomodeling workflows proceed by interpolating the stratigraphic information contained in data points while faults are taken into account by introducing topological discontinuities (Mallet, 2002, Calgagno et al., 2008, Caumon et al., 2009). While such approaches have demonstrated their efficiency and are in daily use by the natural resources industry, they lack an explicit control on kinematics and mechanics, which can lead to implausible structures (Caumon et al., 2013). A validation step is then required for rejecting structurally in- 
compatible models e.g. by simulating the retrodeformation that restores the geological structures to their supposed initial state (Dahlstrom, 1969 Tanner et al., 2003, Moretti et al., 2006; Maerten and Maerten, 2006, Durand-Riard et al. 2010). Even if such approaches have proved their ability to highlight certain structural inconsistencies, they imply a repeated trial-and-error process to achieve a completely kinematically compatible model, which would require prohibitive computational time. For these reasons, the introduction of kinematics and geomechanics remains a major bottleneck of geomodeling workflows, albeit crucial for the predictive capabilities of the models (Fletcher and Pollard, 1999).

Several approaches aim at producing numerical models of structural surfaces that natively honor some geological rules, for example: developability (Thibert et al. 2005), thread geometry of fault surface (Thibaut et al. 1996), sedimentation and compaction rates consistency (Mallet, 2004) and fold models (Kaven et al. 2009, Hjelle and Petersen, 2011). Because 3D displacement patterns associated with natural faults play a prominent role in fault characterization, we suggest that taking them explicitly into account while building the faults is a key aspect to increasing their consistency.

The application of such concepts to uncertainty modeling and to inverse problem solving (Cherpeau et al., 2012, Jessell et al., 2010, Georgsen et al., 2012 ) requires us to express a fault's displacement with appropriate parameters:

- The parameters should preferably correspond to the structural characteristics of geological objects to make their interpretation and use easier.

- They have to be limited in number in order to maintain the dimensionality of these problems to acceptable limits.

This paper presents an approach for parameterizing the faults and their associated displacements in the form of a volumetric vector field, in a spirit similar to Jessell and Valenta (1996) and Georgsen et al. (2012). It consists of an extension of the fault parameterization presented in Cherpeau et al. (2010b, 2012). The proposed approach is based on previous work in Computer Graphics (Von Funck et al. 2006), which was first adapted to geological modeling in an earlier conference paper (Bouziat
2012). Our paper completes this fault parameterization and introduces significant improvements to the methodology with a particular attention to fault kinematics and partitionning between nearfield and far-field deformation.

Our contributions to a complete fault parameterization are:

- The definition of a 3D curvilinear fault space offering a general and appropriate frame for displacement computation (section 3.2).

- The differentiation of the displacement evolution in the three principal directions of a fault: away from fault, along fault in the slip direction and along fault orthogonal to slip direction (section 3.4.

- The ability to combine different flanking structures at different scales around the same fault (Fig. 10).

- The ability to use complex prior information to characterize the displacement field even when few or no data are available.

- The recourse to a time integration scheme to progressively build the displacement (section 3.5, which allows us to combine displacements with different tectonic origins.

We present synthetic applications of this model in a forward modeling context (section 4.1). Its integration into stochastic sequential simulations of fault networks for improving fault data clustering is also depicted (section 4.3). Finally, adaptation to complex fault cases is presented through the example of a roll-over anticline (section 4.2).

\section{Related work}

Numerous approaches have allowed fault-related displacements to be taken into account as an emerging character from either the geometrical interpolation of geological structures due to topological discontinuity introduced by faults (Caumon et al. 2009 ) or the geometrical and mechanical restoration of horizon structures (Egan et al., 1999, Moretti et al., 2006, Maerten and Maerten, 2006, DurandRiard et al., 2010). For a complete fault parameterization, the associated displacements have to be explicitly integrated in the description of the fault.

The context of forward modeling requires fault operators capable of representing all possible ranges 
of displacements along and across faults, even when few or no data are available. To overcome this hurdle, Jessell and Valenta (1996) present several fault operators analytically modeling the 3D displacement fields associated with different kinds of canonical faults. For regional faults going through a studied domain, the displacement fields in fault blocks are modeled as pure translation or rotation. For faults of shorter extent, an elliptical decrease of slip intensity based on Walsh and Watterson (1987) is introduced.

Similar concepts of fault operator have also been developed for model editing in fault uncertainty models (Hollund et al., 2002, Georgsen et al., 2012), using two kinds of fault models: a piece-wise planar model for large faults and an elliptic model for small-scale faults. The curvature of fault surfaces can be accounted for by requiring constant distance between the displaced points and the fault surface (Jessell and Valenta, 1996, Georgsen et al. 2012). Because slip distribution is generally far more complex than depicted by classical elliptical models (Barnett et al. 1987) it is possible to derive the slip field by kriging horizon displacements projected on the medium plane of the fault Georgsen et al., 2012).

In this paper, we present a general model based on the observation that, in spite of the wide diversity of faults, some common characteristics emerge and make it possible to describe them in a unified model, based on two main components:

- a 3D curvilinear fault frame, whose axes are oriented according to the orientation of the fault surface and the displacement direction (detailed in section 3.2.

- the profiles of the attenuation of the displacement along the three axes.

The fault frame makes it possible to map complex fault geometries onto canonical cases, and the attenuation profiles enable the modeling of complex, theoretical and/or observed, displacement patterns. Displacement attenuation profiles are controlled by a limited set of geometric parameters, making this model compatible with both forward modeling and inverse approaches (Cherpeau et al., 2012, Jessell et al., 2010, Georgsen et al. 2012).

\section{A parametric model describing fault- related displacements}

\subsection{General presentation of the model of displace- ments}

The model presented in this section aims at deforming the structures cut by a fault in a kinematically consistent way. It relies on the modeling of the displacement field which represents the effects of the fault on the surrounding structures. Two kinds of displacement fields associated with faults are generally considered (Barnett et al., 1987): the farfield and the near-field, representing respectively the continuous and discontinuous parts of the displacement (Fig. 1).

The far-field describes the global displacement field in which a fault occurs. At the large scale (with regard to the size of a fault) only the far-field is perceptible. At a smaller scale, a fault localizes deformation which enables the accommodation of part of the stress related to the far-field displacements. This accommodation comes in the form of an additional displacement located around the fault, referred to as near-field. This kind of displacement affects the surrounding rocks and produces flanking structures, including normal and reverse drag (Fig. 2). These two terms designate ductile deformation of geological markers cut by a fault. They are distinguished by the direction of the curvature of the resulting folds:

- Normal drag describes a decrease of apparent displacement near the fault surface producing bending towards the opposite direction of the block displacement (Fig. 2a).

- Reverse drag is the opposite phenomenon. It corresponds to an increase of the apparent displacement near the fault surface bending the horizon towards the direction of displacement (Fig. 2p).

The term "normal drag" comes from the similarity with the geometry produced by friction phenomena (Hamblin, 1965, Billings, 1972) and is now well established even if it has been recognized to be misleading (Hamblin, 1965; Hobbs et al., 1976. Grasemann et al., 2005). Indeed, the frictional resistance is unable to properly explain normal drag and would limit the development of reverse drag (Reches and Eidelman, 1995), which seems contradictory to the fact that normal and reverse drag can be observed together on a single fault. 


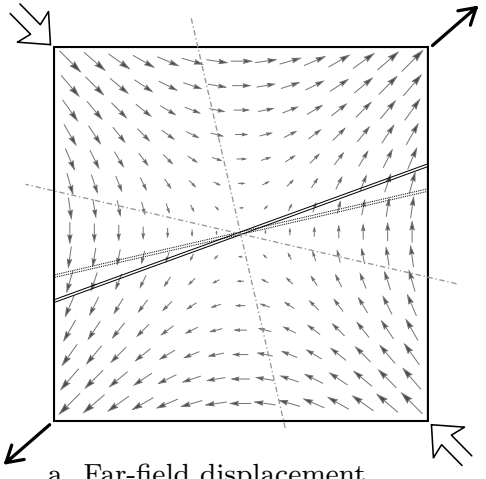

a. Far-field displacement

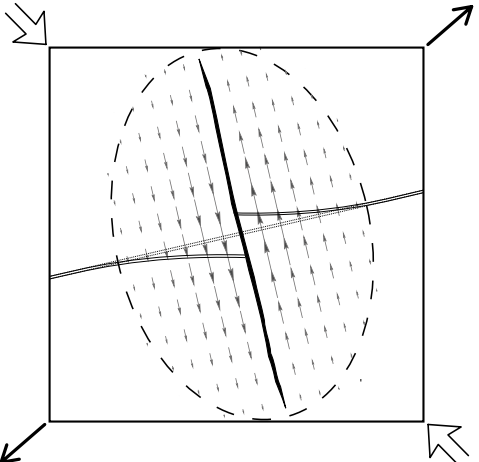

b. Near-field displacement

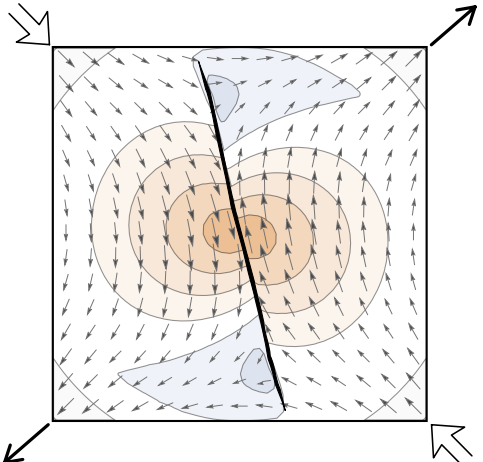

c. Resulting displacement

Figure 1: The different displacement fields related to a fault. a. Far-field: pure shear displacement field with diagonal principal direction (white arrows: shortening, black arrows: elongation). Faults preferentially appear with an angle below $45^{\circ}$ from principal stress direction, depending on the friction coefficient of the host rock (dashed lines: two possible orientations for a fault). In this context, a geological marker (double line) would rotate with an angle depending on the orientation relative to the principal directions. b. Near-field: the development of a fault generates an additional displacement decreasing up to the near-field boundary (dashed line). The attenuation of the near-field displacement causes any orthogonal horizon to form a reverse drag. c. Resulting displacements: the combination of far-field and near-field displacements results in a complex displacement field. The isolines show the distribution of the displacement magnitude (orange is high, blue is low).

The interpretation of fault drag is complicated their diverse origins. The curvature of the fault surface is one of the first general effects accounting for flanking structures, e.g. the roll-over anticlines observed in the hanging-wall of listric faults (Hamblin, 1965). The attenuation of the near-field displacement around faults of limited extent also plays a role in producing flanking structures as it naturally produces reverse drag (Barnett et al., 1987), even for planar faults. Normal drag is also likely to appear due to a low angle intersection between marker and fault (Grasemann et al. 2003, 2005) or due to ductile deformation occurring before or in relation to fault rupture (Reches and Eidelman, 1995).

It is important to notice that normal and reverse drag generally act at different scales, normal drag being localized closer to the faults' surface or tips. The ability to superimpose these two effects with appropriate scales, as demonstrated in Fig. 10, is necessary for an accurate representation of flanking structures.

As in most of the literature, we focus on the nearfield displacement for two reasons:

- The modeling of the far-field is demanding because it cannot be directly deduced from the fault geometry. It depends on the tectonic context and is beyond the scope of this study.

- The near-field is generally predominant in the characterization of flanking structures (Fig. 22).
The observation of faults in the field reveals that actual near-field displacement patterns may be quite complex, for example in the case of faults growing by segment linkage (Walsh et al. 2003 Kim and Sanderson, 2005). Rather than directly taking all possible displacement patterns into account, the model presented here focuses on the description of simple fault patterns, i.e. faults having the following characteristics:

- The displacement intensity is globally decreasing from a point of maximum displacement, referred to as fault center.

- The fault surface and the displacement intensity isolines along the fault surface are roughly circular or elliptical, i.e. convex $2 \mathrm{D}$ shapes with major and minor geometrical axes.

- The displacement direction is parallel to one of these axes.

It is then possible to model more complex displacements by combining several simple fault patterns.

In the present model, finite and infinite faults will be considered with the following assumptions:

- For finite faults, the continuity of displacements of the matter beyond the faults' tip line implies the continuity of the far-field displacements. The discontinuous part of the final displacement field is represented by the near-field 


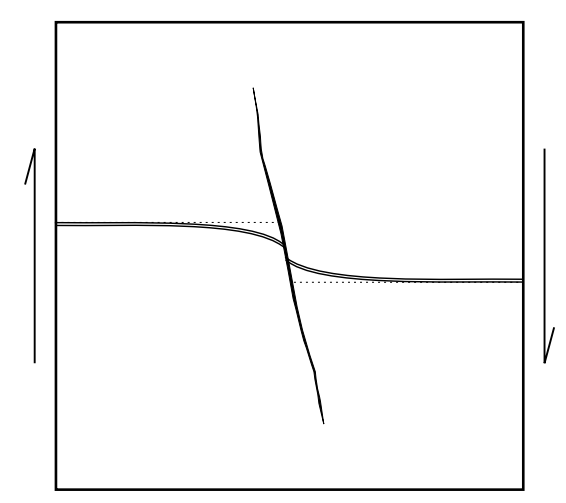

a. Normal drag

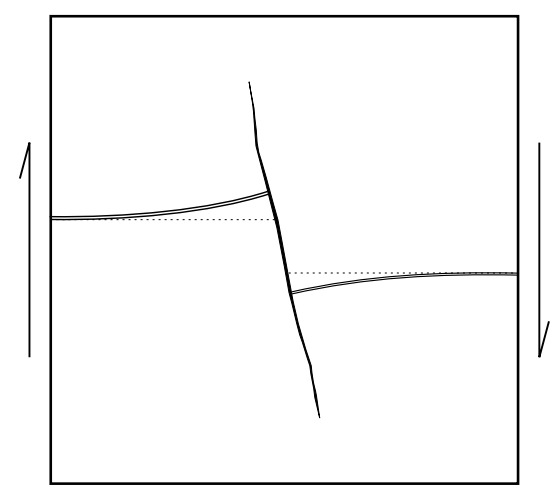

b. Reverse drag

Figure 2: Fault flanking structures. An initially flat horizon is cut by a fault with a normal relative displacement (arrows). This superimposes a ductile deformation (thick line) to the translation of the fault blocks (dashed line). a. Normal drag: bending towards the opposite direction of the block displacement. b. Reverse drag: bending towards the direction of displacement.

displacements. This near-field implies a volumetric strain which can be locally non-zero, but we assume that its values globally compensate inside the envelope of the near-field ensuring the global conservation of rock volume. This condition is however relaxed for faults whose near-field envelope intersects a free surface, such as the topographic surface.

- Very large faults can be considered as infinite with regard to the domain of study. For infinite faults, near- and far-fields are entangled and are considered as a single discontinuous far-field. Some local deformation leading to normal drag of limited extent is also likely to be observed. They are interpreted as residuals of pre- or peri-faulting ductile deformation (Reches and Eidelman, 1995). In our approach, very large faults are represented by a discontinuous far-field with a possible special near-field representing ductile deformation (section 4.2). No assumption on local or global volumes is made because their conservation is not systematic (Means, 1989). These conditions are replaced by assumptions on the extension rate in a given direction.

The computation of the near-field displacement relies on a given fault geometry, a set of structural parameters representing the fault's extent and the profile of attenuation of the displacement in the surrounding rocks. The final displacement is obtained by progressively integrating an instantaneous displacement field $\underline{v}$ over time (section 3.5), which al- lows to account for the variation of the displacement direction and intensity. Furthermore, the calculation of $\underline{v}$ is rendered independent of the fault geometry by using a curvilinear fault frame presented in the next section.

\subsection{D curvilinear fault space}

Despite a large variety of fault types, two principal directions can generally be identified: the direction orthogonal to the fault surface and the direction of slip. Our model implements these observations through the use of a $3 \mathrm{D}$ curvilinear frame $\mathcal{F}$, inspired by the one describing chronostratigraphic coordinates (Moyen et al., 2004, Mallet, 2004). Each of its coordinates is defined by three scalar fields in $3 \mathrm{D}$ space:

- $g_{0}$ : represents both the geometry of the fault surface (iso-surface of value 0) and the signed distance to its surface.

- $g_{1}$ : is defined by the local normal to the fault and the slip direction. It complements $g_{0}$ for representing the displacement direction: along the fault surface, the isolines of $g_{1}$ correspond to the fault striae.

- $g_{2}$ : is a complementary coordinate orthogonal to both $g_{0}$ and $g_{1} \cdot g_{2}$ is used to describe the lateral evolution of the displacement field on the fault surface.

These three coordinates define an implicit mapping between the actual geometry $\mathcal{G}$ and the regular fault space $\mathcal{F}$ where the fault appears as an 
ideal elliptical fault (Fig 3). To complete this mapping, a fault center $C$ is also required. $C$ is chosen as the point of maximum displacement along the fault surface, which facilitates the computation of the displacement profiles (section 3.4).

The distance $D$ to the fault center is defined in the frame $\mathcal{F}$ as the norm of the vector of coordinates $\left(g_{0}, g_{1}, g_{2}\right)$ denoted as $\underline{g}$ :

$$
\forall \underline{g} \in \mathcal{F}, \quad D\left(g_{0}, g_{1}, g_{2}\right)=\sqrt{g_{0}^{2}+g_{1}^{2}+g_{2}^{2}}
$$

For convenience, $g$ is normalized so that $D$ becomes 1 at the boundary of the near-field influence zone (see Fig. 1b).

The fault surface is defined by the positions where: $g_{0}=0$ and $D(\underline{g}) \leq 1$. The tip line of the fault is defined by: $g_{0}=0$ and $D(\underline{g})=1$. An algorithm to obtain adequate coordinates while modeling a fault with a complex geometry is given in section 4.1

\subsection{Constraints on displacement direction}

The direction and polarity of $\underline{v}$ are directly derived from the fault frame $\mathcal{F}$. The definition of $\mathcal{F}$ implies that $\underline{v}$ is parallel to the isovalues of $g_{0}$ and $g_{1}$. This is ensured by computing its direction vector $\underline{u}$ from the cross product of the gradient of these coordinates, respectively denoted $\underline{\nabla g_{0}}$ and $\underline{\nabla g_{1}}$ :

$$
\underline{u}=\frac{\underline{v}}{\|\underline{v}\|}=k \frac{\underline{\nabla g_{0}} \times \underline{\nabla g_{1}}}{\left\|\underline{\nabla g_{0}}\right\| \cdot\left\|\underline{\nabla g_{1}}\right\|}
$$

The factor $k$ in the previous equation denotes the polarity of the displacement. Its sign is the same as the sign of $g_{0}$, which determines in which fault block each point is located. This definition could be problematic for the points laying exactly on the fault surface because their values of $g_{0}$ are exactly 0 . This is addressed by considering the $g_{0}$ value of the neighbors of the problematic points (which implies that the numerical representation of the displaced objects are discontinuous across the fault).

The identification of the fault block is also used when a different behavior is expected on the footwall and the hangingwall of the fault. For example, an uneven repartition of the total relative displacement can be represented by introducing a partition factor $\gamma$ (Georgsen et al., 2012) defined as follow:

$$
\begin{gathered}
\gamma\left(g_{0}\right)=\left\{\begin{array}{rr}
\gamma_{h} & \text { if } g_{0} \geq 0 \\
\gamma_{f} & \text { if } g_{0}<0
\end{array}\right. \\
\text { with } \\
\gamma_{h}=1-\gamma_{f}
\end{gathered}
$$

$\gamma_{h}$ and $\gamma_{f}$ are the ratio of the relative displacement affected respectively to the hangingwall and the footwall. One of the fault blocks can also be fixed, setting $\gamma_{h}$ or $\gamma_{f}$ to 0 , in order to apply the complete displacement on the other fault block.

It is possible to model more complex displacements, as presented by Grasemann et al. (2005), with this framework, for instance by adding a displacement component orthogonal to $g_{0}$. Also, in certain cases, the displacement direction may not be parallel to the minor or major axis of the fault surface, as required in section 3. Such fault can be handled by creating $g_{1}$ and $g_{2}$ according to the fault surface axis and by rotating these coordinates around $C$ before the computation of $\underline{u}$.

\subsection{Displacement attenuation profiles}

The amplitude of the near-field displacement is supposed to be maximum at a certain point $C$ of the fault surface and it decreases to zero up to a certain distance (Fig. 1p). The profile $p\left(g_{0}, g_{1}, g_{2}\right)$ of the displacement attenuation evolves differently in each principal direction of $\mathcal{F}$. Three profiles $p_{0}\left(g_{0}\right)$, $p_{1}\left(g_{1}\right)$ and $p_{2}\left(g_{2}\right)$ are introduced in order to explicitly control the attenuation in the directions $g_{0}, g_{1}$ and $g_{2}$ respectively.

The amplitude of $\underline{v}$ is computed by multiplying the maximum displacement $v_{\max }$ at $C$ by a partition factor $\gamma$ and an attenuation function $\rho$ :

$$
\|\underline{v}\|=v_{\max } \gamma\left(g_{0}\right) \rho\left(g_{0}, g_{1}, g_{2}\right)
$$

The attenuation function $\rho$ is computed from the attenuation profiles by applying the following steps:

- The attenuation due to the position along the fault surface is first computed by combining $p_{1}\left(g_{1}\right)$ and $p_{2}\left(g_{2}\right)$ so that $\rho\left(0, g_{1}, g_{2}\right)$ evolves progressively from $p_{1}\left(g_{1}\right)$ where $g_{2}$ equals 0 to $p_{2}\left(g_{2}\right)$ where $g_{1}$ equals 0 . This is obtained by considering the polar coordinates $(r, \alpha)$ in the fault surface, where $r$ denotes the distance between a point $\left(g_{1}, g_{2}\right)$ and the center $C$ and $\alpha$ the angle between this point and the axis $g_{1}$ :

$$
\rho\left(0, g_{1}, g_{2}\right)=p_{1}(r) \cos ^{2}(\alpha)+p_{2}(r) \sin ^{2}(\alpha)
$$

$$
\text { with } \begin{aligned}
r= & \sqrt{g_{1}^{2}+g_{2}^{2}} \\
\cos ^{2}(\alpha) & =g_{1}^{2} / g_{1}^{2}+g_{2}^{2} \\
\sin ^{2}(\alpha) & =g_{2}^{2} / g_{1}^{2}+g_{2}^{2}
\end{aligned}
$$




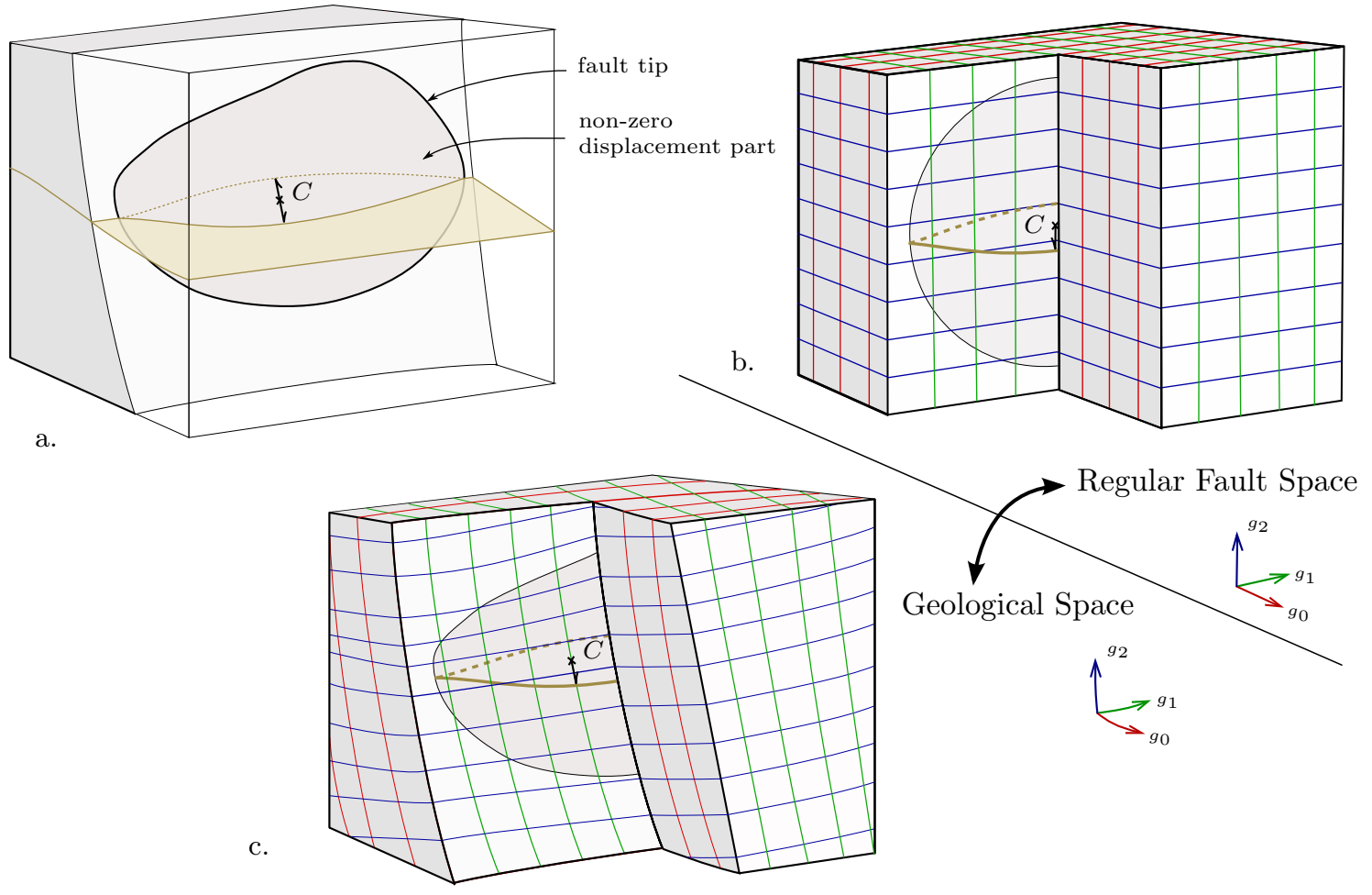

Figure 3: The fault coordinate system. a: A block diagram with a fault cutting a horizon, $C$ denoting the point of maximum displacement. The shaded surface represents the zone with a non-zero displacement delimited by the fault tip (plain line). $b$ and c: The $3 \mathrm{D}$ curvilinear fault frame with its 3 coordinates: $g_{0}$ (red), $g_{1}$ (green), $g_{2}$ (blue). It describes an implicit mapping between the actual curvilinear geological space (c) and a regular fault space (b), which simplifies the description of the fault.

- The effect of the attenuation due to the distance to the fault surface following $g_{0}$ is then taken into account by multiplying by $p_{0}\left(g_{0}\right)$ :

$$
\rho\left(g_{0}, g_{1}, g_{2}\right)=p_{0}\left(g_{0}\right) \frac{p_{1}(r) g_{1}^{2}+p_{2}(r) g_{2}^{2}}{g_{1}^{2}+g_{2}^{2}}
$$

An example of profiles honoring basic geological conditions is depicted in Fig. 4. They can be adapted to specific observations and models of profiles along and across fault (Barnett et al. 1987. Walsh and Watterson, 1987; Reches and Eidelman 1995: Cowie and Shipton, 1998). In our implementation, a polynomial spline is used for interactively editing the profiles by modifying the slope at the extremities and introducing control points.

It is possible to obtain more complex profiles by mixing several simple profiles. For example, the profiles presented in Hamblin (1965), where superimposed reverse and normal drag are observed, are modeled by linearly combining two profiles with different fault drag radii. Profiles resulting from segment-linkage can also be implemented by combining several simple profiles with centers placed at different locations.

\subsection{Time integration of the instantaneous displace- ment field}

As the magnitude and direction of the displacement fields change along the fault, we propose to use a discrete time scheme in order to integrate instantaneous displacement steps instead of directly considering the complete displacement. This approach has numerous interesting properties (Theisel et al., 2005, Von Funck et al., 2006), with appropriate displacement fields and time steps:

- It avoids non-physical self-intersection of the displaced material.

- It keeps the detailed geometry and continuity of the surrounding structures. 


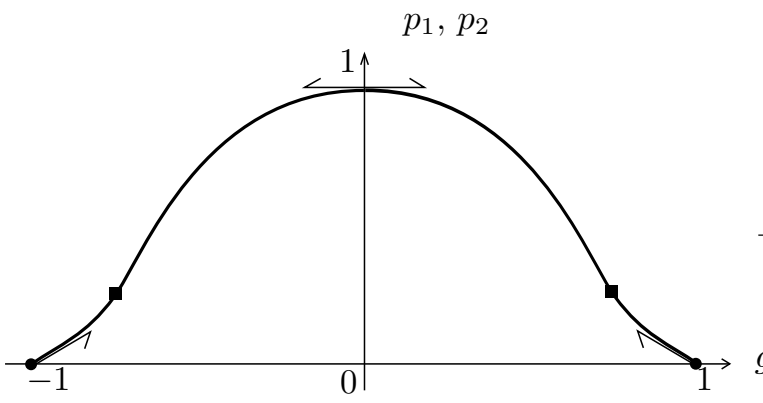

a. Profiles of $p_{1}$ and $p_{2}$

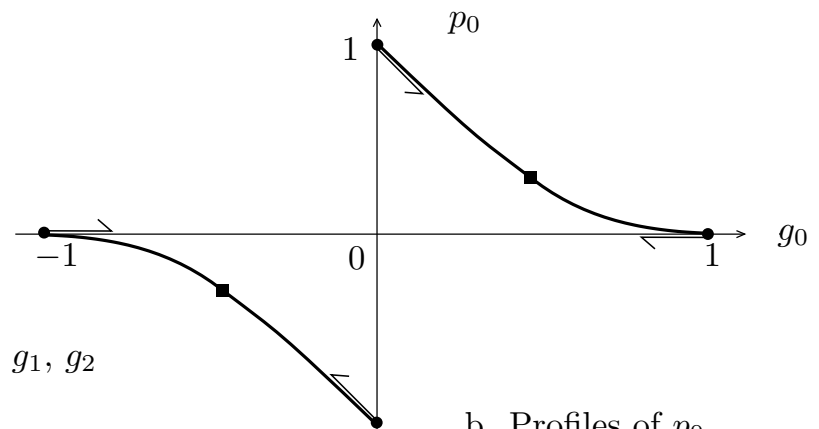

b. Profiles of $p_{0}$

Figure 4: An example of attenuation profiles. The curve on the left presents the attenuation followed by $p_{1}$ and $p_{2}$, i.e. along the fault surface. A bell-shaped profile (Cowie and Shipton, 1998) is represented here, but other profiles could be used instead. The curve on the right represents $p_{0}$, with a profile close to the profiles presented in Barnett et al. (1987). The value of the derivatives are controlled at the extremities and center of the profiles (arrows) and additional control points can be introduced in order to tune the curves (squares). Note that $p_{0}$ is represented as negative for $g_{0}<0$ (this behavior is managed by the factor $k$ in eq. 2)

In addition, it is consistent with fault behavior, whereby observed displacements generally result from one or a succession of relatively continuous displacement events.

The time integration process is performed by successively summing up the small displacements computed over small time steps. The duration of the time step $\tau$ is determined at the beginning of the process. It is expressed as a percentage of the total displacement duration. It can be refined to better fit the curvature of the fault or to adapt to the displacement intensity variations and to the deformed object discretization.

The fault frame is initialized by computing $g_{0}, g_{1}$ and $g_{2}$ (see section 4.1). For each point of each object to be deformed, the corresponding fault block is computed by affecting the sign of $g_{0}$ to the variable $k$. Then, for each time step $\tau$ :

- If the geometry of the fault or its structural parameters have changed, the fault frame is updated.

- For each point $X$ :

- The direction of the displacement vector $\underline{u}$ is evaluated from eq. 2).

- The intensity of displacement $\|\underline{v}\|$ is evaluated from eq.(5).

- The position of the point is updated: $X \leftarrow X+\tau\|\underline{v}\| \underline{u}$

Another interesting aspect of this approach is that it is possible to accumulate the effect of several tectonic elements, as long as an instantaneous displacement field can be provided. For example, it is possible to accumulate several faults acting simultaneously (Fig. 6). This is also a way to integrate the far-field effect as demonstrated in figure 8

\section{Application}

\subsection{Deformation of horizons cut by finite faults}

This section presents some examples of the application of our method. A first basic example illustrates the effects of a single fault of limited extent on a volumetric stratigraphic sequence (Fig. 5). Because the fault is planar, the fault frame is obtained by taking the distance to the fault center in the three principal directions of the fault. These directions correspond to the normal of the fault plane for $g_{0}$, the direction of slip $g_{1}$ and their orthogonal direction $g_{2}$.

The second example (Fig. 6) presents a more complete application with two non-planar faults simulated by a parametric approach (Cherpeau et al. 2010b, 2012).

In this case, the fault coordinates are computed by a constrained interpolation process (Frank et al. 2007; Caumon et al., 2012 (in press) . $g_{0}$ is an output of the parametric simulation of the geometry of the fault. $g_{1}$ and $g_{2}$ are extrapolated from the fault center with the following constraints:

- The values of $g_{1}$ and $g_{2}$ are 0 at the fault center C.

- $\underline{\nabla} g_{1}$ is orthogonal to the slip direction. 


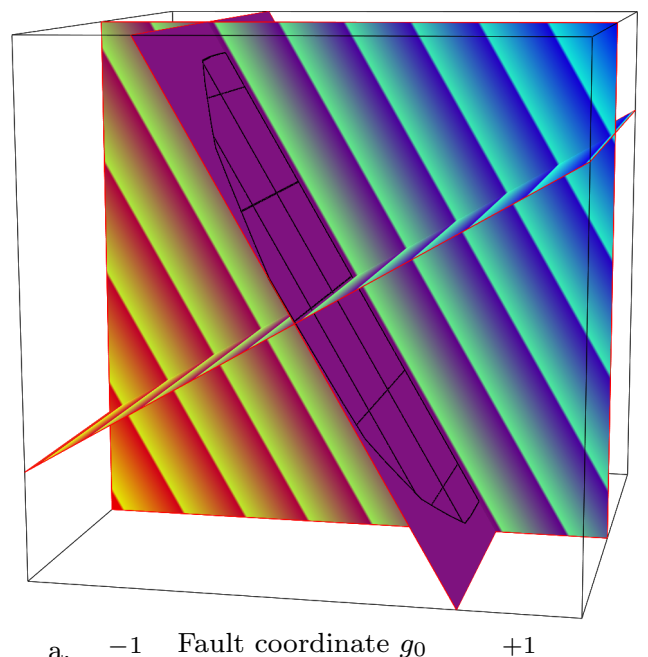

a. $\quad-1 \quad$ Fault coordinate $g_{0} \quad+1$

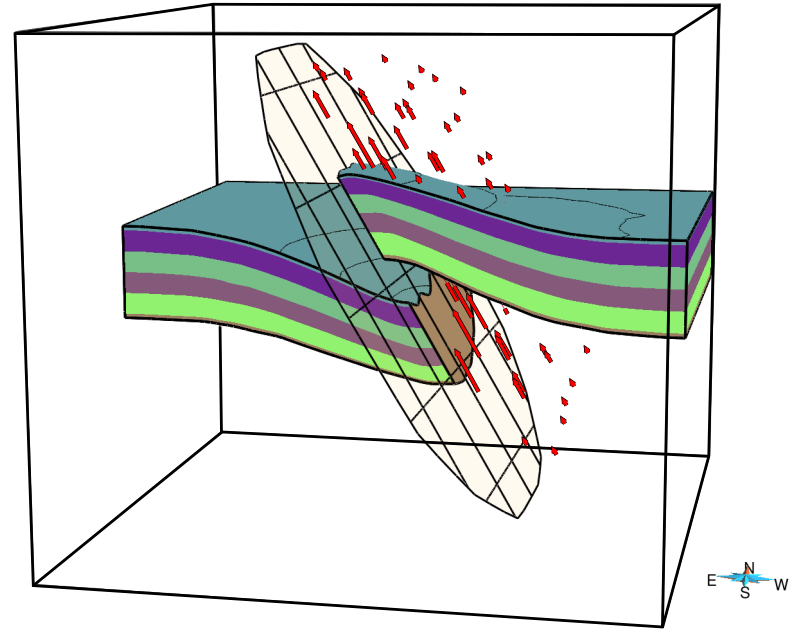

b. Deformed layers

Figure 5: Single fault example. a: The fault frame used to compute the displacement associated with this fault. b: The deformation resulting from the application of the near-field displacement on initially horizontal layers, red arrows show local displacement vectors.

- The gradient of the three coordinates are mutually orthogonal, which is ensured by setting: $\underline{\nabla g_{1}} \perp \underline{\nabla g_{0}}, \underline{\nabla g_{2}} \perp \underline{\nabla g_{0}}$ and $\underline{\nabla g_{2}} \perp \nabla g_{1}$.

- The norm of the gradients is set to 1 at $C$.

The coordinates are finally normalized by dividing $g_{1}$ and $g_{2}$ by their extreme values observed on the border of the fault and $g_{0}$ by its values observed at a specified distance from the fault center. The fault coordinates used for Fig. 6, before and after normalization, are presented in Fig. 7.

The near-field displacement alone is generally not sufficient to consistently model the geometry of faulted stratigraphic horizons. Indeed, it only represents additional deformation made possible by the mechanical discontinuity of the fault, but the source of this displacement most often comes from the far-field conditions. Deformations representing only the near-field may seem artificial for this reason and taking the far-field into account is necessary to obtain useful models.

We consider two possibilities to take the far-field into account:

- Data driven approach: which consists of building continuous horizons first, by interpolating the stratigraphic data (Caumon et al., 2009), and then applying the fault operator to add the near-field displacements to the model. With this approach, the far-field is not modeled explicitly but its effect is implicitly accounted for by relying on the data. Therefore, this modeling strategy does not highlight the link between the observable continuous deformation and the actual far-field related to the fault operator. For example, folds appearing before or after the faulting are ignored, possibly leading to inconsistent results. The evolution of the fault can not be represented properly as the integration does not start with an actual geometry of the horizon. Also there is no guaranty that the parameters used to describe the near-field displacements are consistent with the underlying far-field displacements contained in the continuous horizon. Nevertheless, this aproach is a pragmatic modeling choice because it directly honors stratigraphic data.

- Process oriented approach: which starts with an initial horizon geometry, possibly integrating hypothesis on preexisting faults and folds. The far-field displacements are then modeled as an additional vector field, which is superimposed on the near-field displacements during the time integration process (Fig. 8). This approach is more consistent with fault's kinematic than the data driven approach, but, as mentioned earlier, the parameterization of 


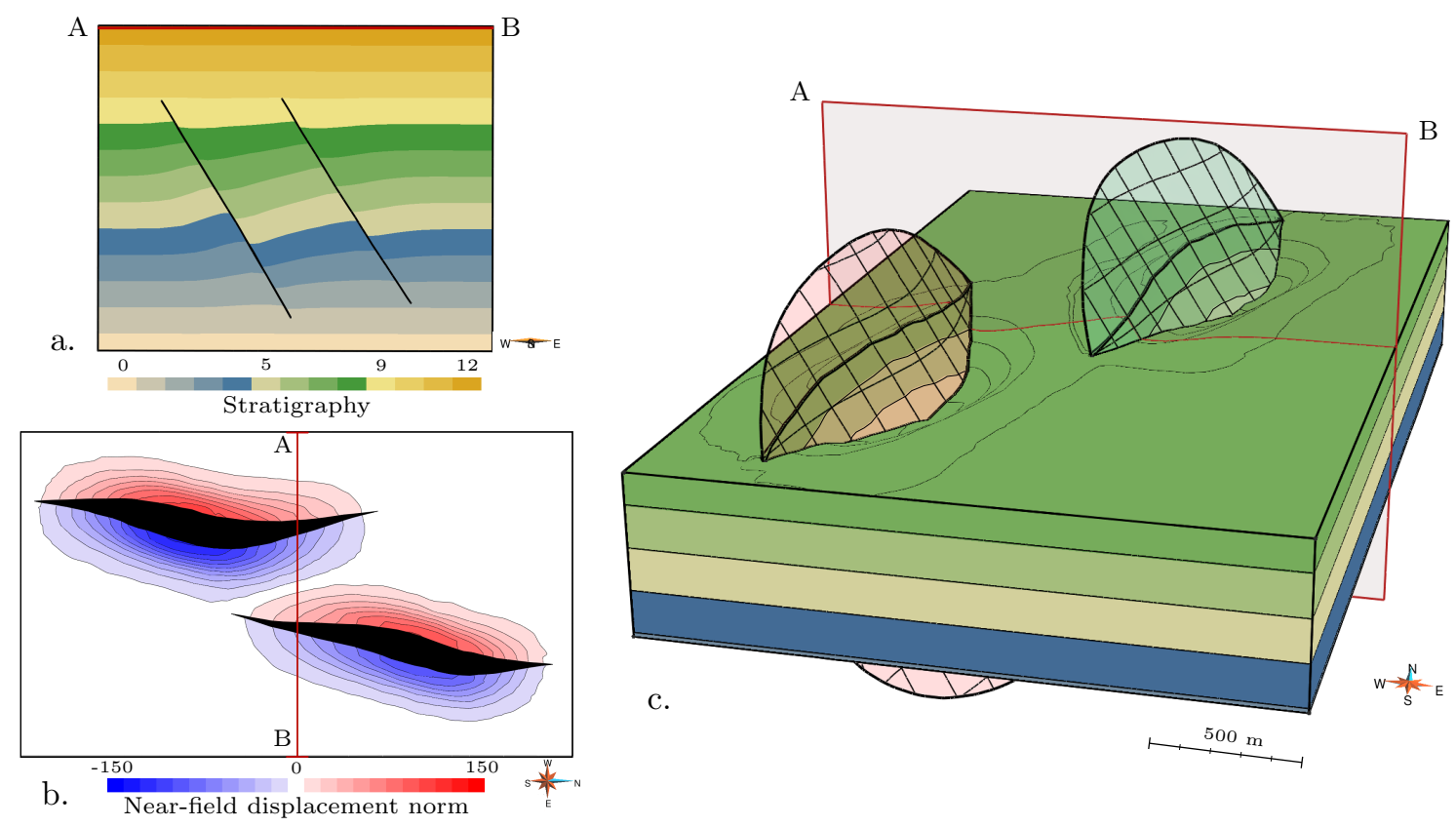

Figure 6: Near-field deformation on two co-genetic normal faults. The far-field has not been applied here to have a clearer view of the near-field modeling (see Fig. 8 for the complete displacement). a: Cross-section showing the stratigraphic horizons affected by the two faults. b: Top view presenting the near-field displacement norm (in meters), i.e. the magnitude of the displacement in 3 dimensions. c: View of the 3D model illustrating the displacement of the horizons affected by the two non-planar faults. Only the layers 4 to 8 are represented in order to make the internal deformation visible. Contour lines representing the elevation are drawn on the top of the layers with an interval of 35 meters.

the far-field is delicate, especially concerning the data conditionning. This latter problem should be addressed by an inverse approach as in Allmendinger (1998); Cardozo and Aanon$\operatorname{sen}(2009)$.

The second approach makes it possible to take into account the displacement and deformation of the fault surface during the deformation. These displacements change the way the fault affects the surrounding horizons and finally their resulting geometry. Indeed, the evolution of the angle between the fault and the horizons potentially changes the fault drag mode during deformation, from reverse to normal drag or vice versa (Grasemann et al. 2003).

\subsection{Large faults and non-planar faults}

The treatment of large faults slightly differs from the computation of a short fault displacement field. The profile should be of infinite extension to obtain a constant displacement intensity in each fault block. Only $g_{0}$ and $g_{1}$ are then needed to control the direction of the displacement.
However, with the increase of the displacement intensity, normal drag can become visible (Hamblin, 1965, Reches and Eidelman, 1995). One way to model this consists of introducing an additional profile following $g_{0}$ with a limiting effect on the displacement intensity (Fig. 10). This profile is either applied during the deformation, to model possible frictional phenomena, or all at once at the end or at the beginning of the time integration process in order to represent pre- or peri-faulting ductile deformation (Reches and Eidelman, 1995).

The accentuated curvature of the fault surface produces reverse or normal drag that are not directly explained by the attenuation of the displacement orthogonally to the fault, such as roll-over anticlines observed in the down-thrown block of listric faults (Hamblin, 1965). We propose to account for such phenomena by adapting the displacement intensity to the geometry of the fault. The direction of the displacement field is computed as usual with eq.(2). The intensity of $\underline{v}$ is locally adapted to ensure that the curvature of the fault is respected and that the displacement path does not diverge 

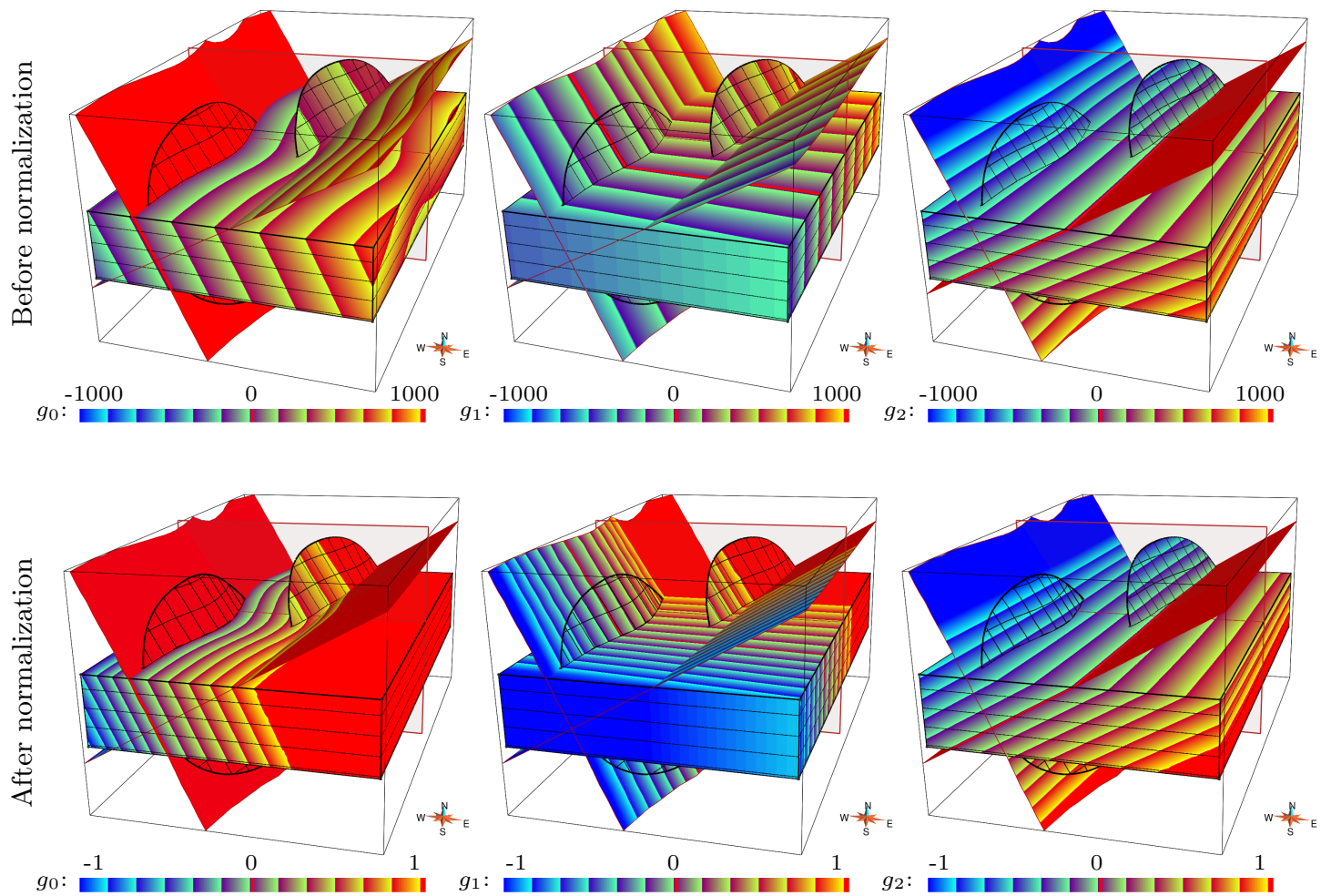

Figure 7: The fault frame coordinates used for the red fault of Fig. 6 Each picture displays the layers to be deformed, the two faults and the isosurfaces $g_{0}=0$ and $g_{1}=0$. On the first row they are respectively painted with $g_{0}, g_{1}$ and $g_{2}$ before their normalization. The second row presents the result of the normalization for each coordinate. The values bigger than 1 or smaller than -1 are painted in red and blue respectively.

from the fault surface during the time integration. A global displacement vector $\underline{V}$ is associated with each fault block. For example, $\underline{V}$ can be deduced from regional knowledge about extension rate in a rifting context. $\underline{v}$ is then integrated until each part of the fault block has been displaced by a distance $\|\underline{V}\|$ in the direction of $\underline{V}$ :

$$
\frac{\left(x-x_{0}\right) \cdot \underline{V}}{\|\underline{V}\|}=\|\underline{V}\|
$$

where $x$ is the current position of a displaced point and $x_{0}$ its original position. This process corresponds to vertical or inclined shear hypothesis (Yamada and McClay, 2003), depending on the inclination of $\underline{V}$.

The algorithm presented in figure 9 is applied to integrate the displacements until this criterion is reached. An example of the application of this algorithm is given in figure 10

\subsection{Taking fault displacements into account in stochastic fault network modeling}

In the context of geological mapping and natural ressource management, the incomplete observations for building quantitative subsurface geomodels raise significant uncertainties about structural geometries. As a consequence, several interpretations are generally possible. Deterministic approaches, relying on a single geomodel, are then inadequate to properly represent subsurface uncertainties. A better sampling of the possible models can be obtained by stochastic approaches which generate series of equiprobable models honoring available data and generated though prior statistical distributions taken from analog studies.

Fault networks are generally particularly sensitive to uncertainty (number of faults, dimensions, connectivity... ) with dramatic impact on rock volume and fluid flow predictions, which justify the use of stochastic approach to fault network modeling (Hollund et al. 2002, Holden et al., 2003. 


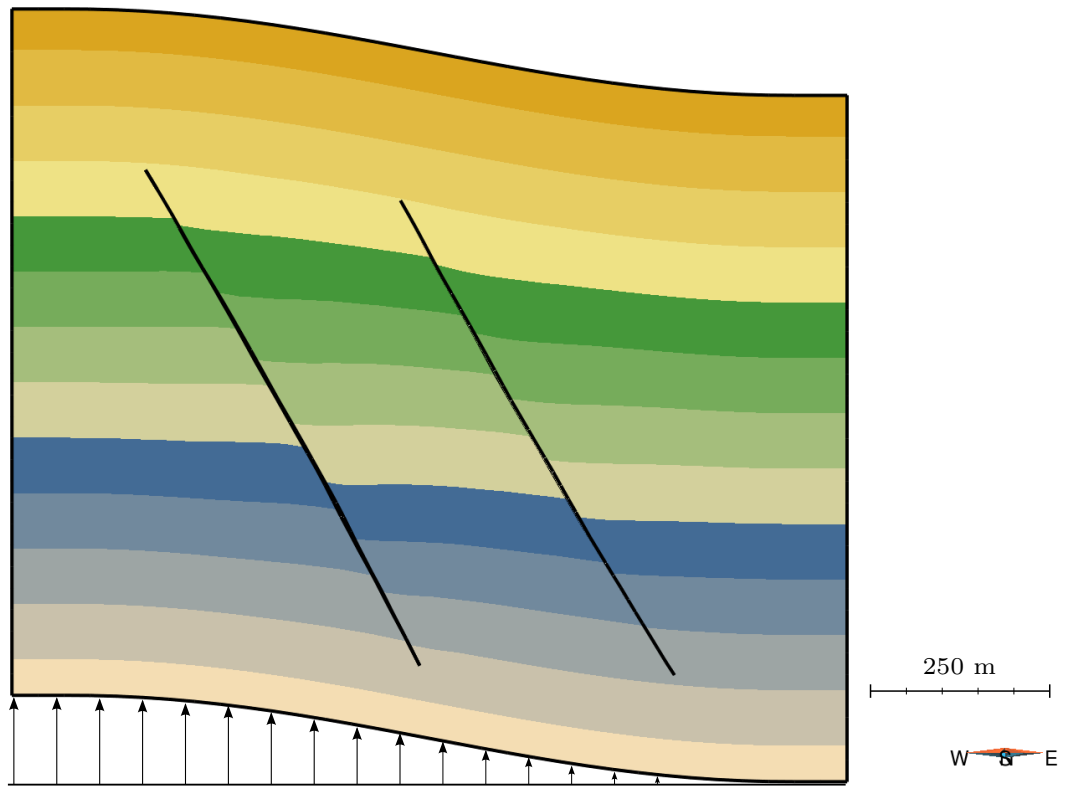

Figure 8: Combination of continuous far-field and discontinuous near-field displacements. Stratigraphic horizon are cut and displaced by two normal faults while they are affected by a global vertical shear (black arrows). This far-field is expressed as a $3 \mathrm{D}$ vectorial field and integrated over time in the same way as the near-field displacement associated with faults. The near-fields used here are similar to those of Fig. 6. The down-thrown blocks undergo 65 percent of the relative displacement for each fault.

Cherpeau et al., 2010a b, 2012). Interpreted seismic sections (Fig. 11/ ) represent typical data used for fault network modeling. They contain fault sticks, i.e. groups of fault markers localizing the discontinuity introduced by faults in the seismic reflectors. Because of the lack of information between the cross-sections, the number of faults and the way fault surfaces connect the different fault sticks can be highly uncertain.

To address these types of uncertainty, Cherpeau et al. (2010a b) suggests generating faults sequentially by randomly drawing a set of geometric parameters from conditional probability distributions. These parameters describe the position of the fault center, its strike, dip, sinuosity and extension in strike and dip directions. Each set of parameter values allows us to define a fault surface, whose geometry can be adapted to fit fault sticks located close to the fault surface. Starting from an initially regular surface, the fault is deformed to fit each compatible fault stick. The evaluation of the compatibility of each fault stick is based on its location, on the curvature its integration would produce and on the intensity and orientation of the displacement observed along the stick. This step, called fault stick clustering, is crucial to ensure the likelihood of the output structural model.

Figure 11 presents an application of stochastic fault networks construction based on a simple data set of 2 synthetic cross sections. In this example, two kinds of faults are expected:

- Family 1: a first generation of normal faults with a NW-SE orientation dipping to the NE (yellow and blue sticks).

- Family 2: a second generation of vertical strike slip faults oriented N-S (green sticks).

The data clustering step determines if a given fault trace can be explained by, and thus associated with, the fault being currently modeled. Here, the number of faults to be modeled from family 1 is particularly uncertain. This family could produce a single fault, gathering yellow and blue sticks, or two isolated faults, which affects the connectivity of the fault network.

Among other criteria, the fault trace position is inspected and its consistency with the current geometry of the fault is checked. However, this position may have been assigned by the displacement 


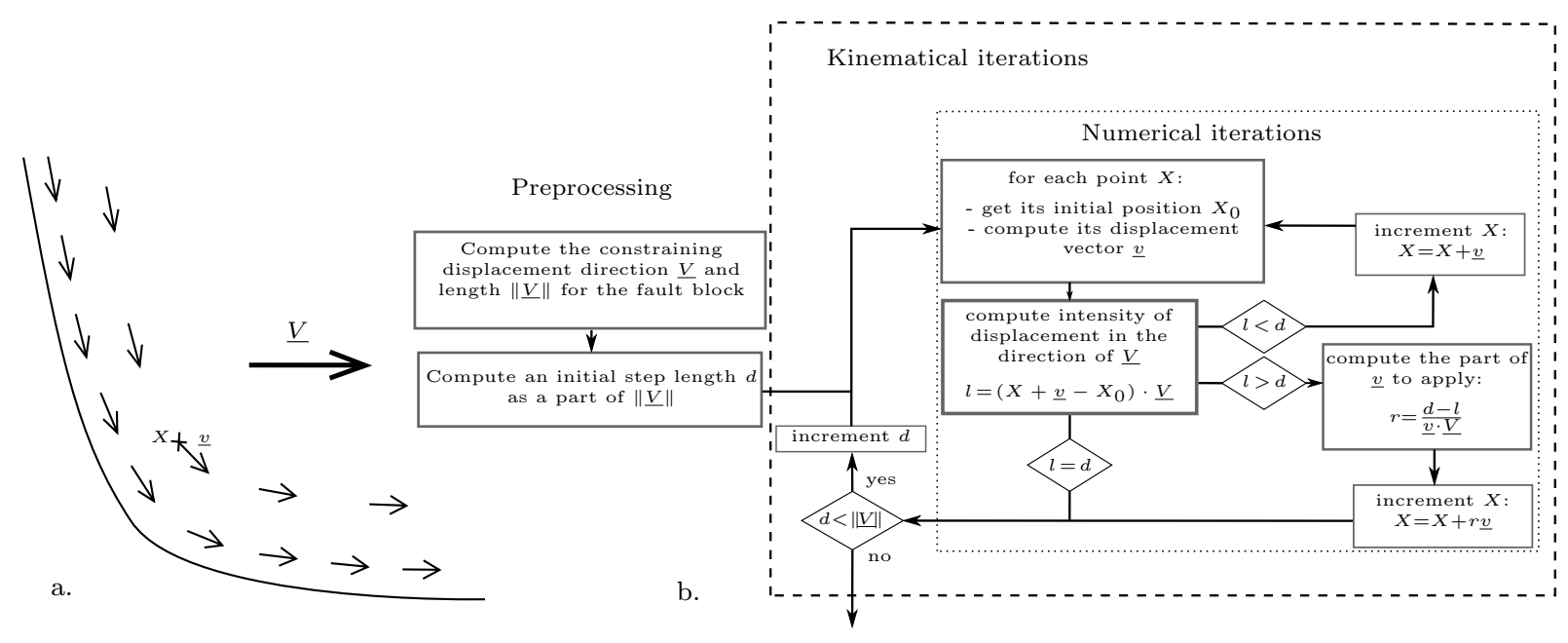

Figure 9: Algorithm of displacement integration for large faults. a: A cross-section view of a listric fault (solid line) with the global displacement constraint $(V)$ and an example of point $(X)$ affected by the algorithm presented on the right part with its displacement step $(v)$. b: The algorithm for integrating non-planar faults. Each point is progressively displaced until a global displacement target has been reached in the constraint direction. The numerical iterations increment the position of the point with a vector of limited displacement in order to ensure a good integration with the curved part of the fault. This step is repeated for each point until a portion $d$ of the target displacement has been obtained, which represents a kinematic step. During the numerical iterations of a kinematic step, certain points may have reached this criterion while some others are still being updated. For this reason, the geometry observed before the end of each kinematic step is not representative of a possible natural geometry, but the results of successive kinematic steps represent the evolution of the fault block during the activity of the fault.

implied by the presence of the youngest faults in the network, which is generally not considered. In the example this results in the construction of three faults (Fig. 11, Scenario 1): two faults of family 1 (yellow and blue) are first generated, then a large fault of family 2 is created (green). The yellow and blue sticks are attributed to two separate faults. Indeed, the algorithm of Cherpeau et al. (2010a) does not detect that they may correspond to a single older fault.

One can argue that the way the yellow and the green faults intersect may look inappropriate here. It is possible to adapt the geometry of the green fault or to remove the superfluous part from the yellow fault, but the yellow and the blue faults will remain considered as two distinct faults.

For better kinematic consistency, the displacement field associated with the youngest faults can be considered while simulating the older ones. For this we propose to start with the youngest faults and to go back in time while sequentially modifying the older fault information with the computed displacement fields. Applying this concept to the present example tends to align yellow and blue markers. The probability that they correspond to a single fault thus becomes non-neglegible (Fig. 11 . Scenario 2).

Even if the two results are similar in terms of number of fault parts, gathering yellow and blue sticks increases the possible size of the faults of family 1 . This also alters the geometry and contact length of the fault networks. Considering the displacement field would then influence the capability of faults to act as drains if the fault are permeable, or would increase the compartmentalization of the fault block if the faults are sealing.

The difference between the two approaches is even more important when considering the implication on the connectivity of the reservoir in the past. Ignoring the effect of younger faults during the clustering step produces a model that implies a rather strong connectivity between the north and south compartments. On the contrary, scenario 2 tends to consider that they were already disconnected after the appearance of the family 1 fault. Such information provides a crucial insight in the understanding of the past circulation of oil or mineralizing fluids. 


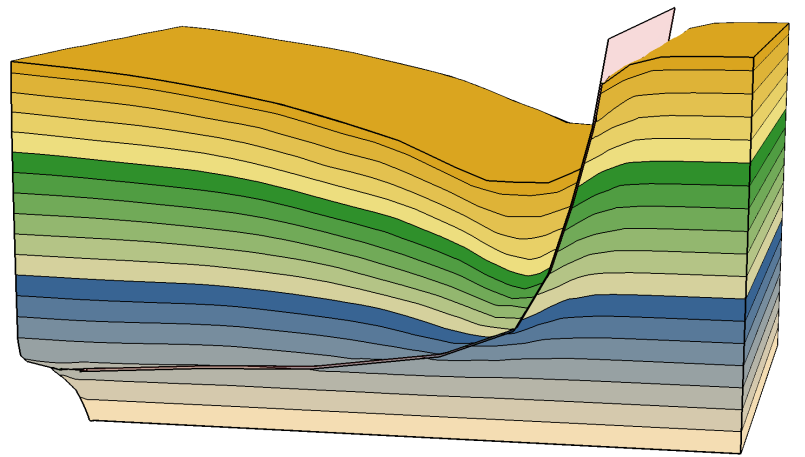

a. Simulated
W

$\mathrm{E}$

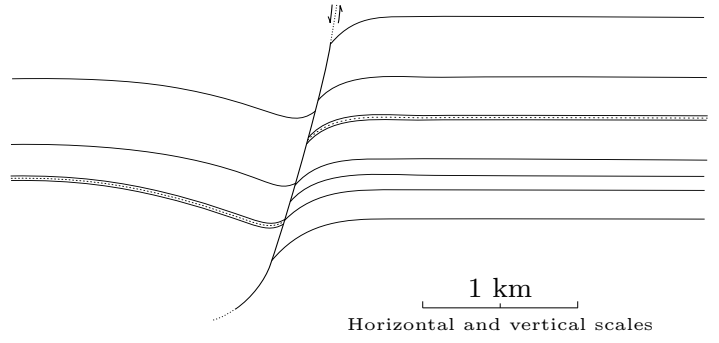

b. Outcrops observations (adapted from Hamblin $(\underline{\underline{1065}})$ )

Figure 10: Listric fault displacement field. This figure presents the results of the deformation associated with a listric fault. The numerical model (a) is designed to reproduce typical folds observed in the flanks of natural listric faults (b): a normal drag, present in both blocks, and a reverse drag, in the hanging wall only, forming a roll-over anticline. The normal drag is interpreted here has the heritage of a fault-propagation fold (Reches and Eidelman. 1995). It is obtained by adapting the attenuation profile to produce a continuous shear parallel to the fault applied at the beginning of the deformation process. The hanging wall is progressively affected by a displacement vector field following eq. 2, until a global displacement of $250 \mathrm{~m}$ to the West is reached (see algorithm Fig. 9. This process produces a roll-over anticline. It is not imposed explicitly but represents an emergent character implied by the fault geometry. The simulated roll-over anticline and the normal drag (a) are similar to those observed in the natural fault depicted in Hamblin (1965) (b). Note that the fault in this example has been chosen for its well identified normal drag and roll-over anticline. This case may not be representative of most listric faults due to the accentuated difference of dip between the top and bottom parts of the fault.

\section{Conclusions}

The method presented in this paper provides a way to parametrize in a 3-dimensional space the deformation associated with faults together with their geometry. This parametrization allows us to apply various models of fault-related displacements in order to deform geological structures affected by normal, reverse or strike-slip faults in a kinematically consistent way. The principal target applications for this parameterization are creating and editing structural models and matching structural parameters to indirect subsurface data, for example history matching (Cherpeau et al. 2012) or potential inversion (Guillen et al., 2008). Such applications would gain in geological consistency by including more kinematic concepts in the construction of structural models, thereby alleviating the quality control and model editing task.

The key elements of this method lie in the explicit control of the displacements intensity, thanks to attenuation profile $p$, the time integration approach to the displacement computation, and the curvilinear fault frame used for describing the fault, resulting in a complete 3 -dimensional volumetric displacement field. This displacement field represents a basic fault operator suitable for loosely interact- ing faults and can be altered and combined in order to fit more complex fault behavior, for example large listric faults (Fig. 9 and 10). It also offers the possibility of investigating further the time-varying aspect of the fault. For instance, syn-sedimentary faults or active structures could be better represented by progressively increasing the part of the stratigraphic sequence affected by the fault during the time-integration.

The approach presented here represents one more step towards an early integration of structural concepts in geomodeling workflows. This paradigm consists in identifying the tectonic components that impact the model, describing their effect in term of instantaneous displacement field and finally summing them by integrating the displacement field over time. The underlying hypothesis of such an approach is that tectonic features can be considered as independent, which is a rather strong assumption. However, it offers the opportunity to create first-order kinematically consistent quantitative models without relying on mechanical simulation, which generally implies a higher computational cost. Nevertheless, future work will focus on introducing interdependent tectonic features in our modeling approach in order to remove this requirement, for example by including the results of sev- 


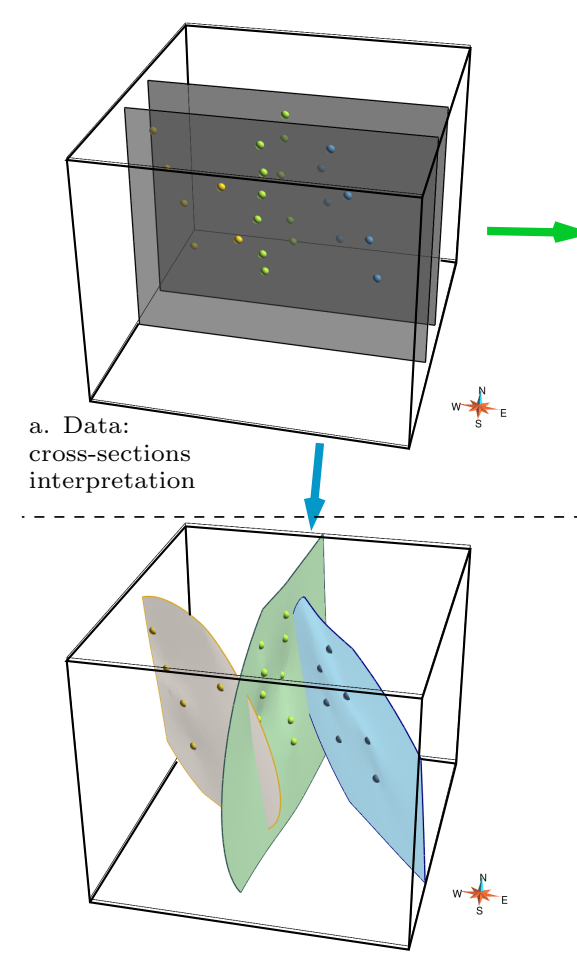

Scenario 1: fault network simulation without taking fault's displacement into account.

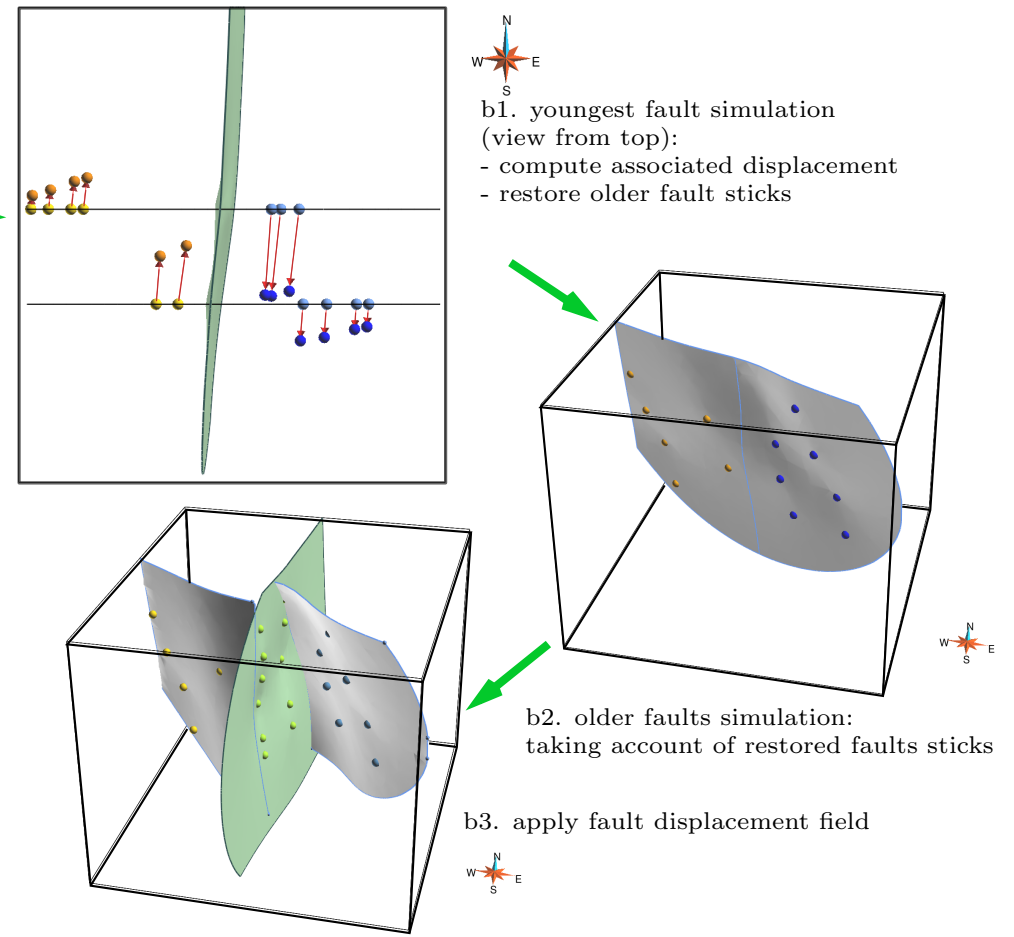

Scenario 2: fault network simulation

+ sequential data restoration

Figure 11: An example taking a fault's displacements into account in sequential fault simulation. a: Synthetic data used in this example, two cross-sections (black) with three groups of fault sticks (yellow, green and blue spheres). Scenario 1: the possible effects of the displacement field are not taken into account. Scenario 2: the older fault sticks (yellow and blue) are restored before being interpreted as a fault. b1: A fault of family 2 is modeled (green) together with its displacement field (red vectors). The fault sticks of family 2 are unfaulted by applying the displacement field. b2: After unfaulting the yellow and blue fault sticks appear to be sufficiently aligned to be gathered in one single fault. b3: The fault of family 1 produced this way is then cut by the green fault and displaced. The resulting fault network is more consistent with the kinematics implied by the faults.

eral mechanical studies of fault interaction: faults intersection (Maerten et al., 1999), relay (Walsh et al. 1999, Soliva et al. 2008) and linkage (Kim and Sanderson, 2005: Walsh et al., 2002).

\section{Acknowledgments}

The authors are grateful to the academic and industrial sponsors of the Gocad Consortium managed by ASGA (Association Scientifique pour la Géologie et ses Applications) for funding this work, and to Paradigm Geophysical for providing the Gocad software and API. We would also like to thank Dr Laurent Aillères for constructive comments which helped improve this paper. This work was performed in the framework of the "Investisse- ments d'avenir" Labex RESSOURCES21 (ANR-10LABX-21).

\section{References}

Allmendinger, R., 1998. Inverse and forward numerical modeling of trishear fault-propagation folds. Tectonics 17 (4), 640-656.

Barnett, J., Mortimer, J., Rippon, J., Walsh, J., Watterson, J., 1987. Displacement geometry in the volume containing a single normal fault. AAPG Bulletin 71 (8), 925-937.

Billings, M., 1972. Structural geology. Prentice-Hall.

Bouziat, A., 2012. Vector field based fault modelling and stratigraphic horizons deformation. In: proceedings of the SPE Annual Technical Conference and Exhibition.

Calgagno, P., Chilès, J., G.Courrioux, Guillen, A., 2008. Geological modelling from field data and geological knowledge part i. modelling method coupling 3D potential-field interpolation and geological rules. Physics of the Earth and Planetary Interiors 171, 147157. 
Cardozo, N., Aanonsen, S., 2009. Optimized trishear inverse modeling. Journal of Structural Geology 31 (6), 546 - 560.

Caumon, G., Collon-Drouaillet, P., Le Carlier de Veslud, C., Viseur, S., Sausse, J., 2009. Surface-based 3D modeling of geological structures. Mathematical Geosciences 41 (8), 927-945.

Caumon, G., Gray, G. G., Antoine, C., Titeux, M.-O., 2012 (in press). 3d implicit stratigraphic model building from remote sensing data on tetrahedral meshes: theory and application to a regional model of la popa basin, ne mexico. IEEE Transactions on Geoscience and Remote Sensing

Caumon, G., Laurent, G., Pellerin, J., Cherpeau, N., Lallier, F., Merland, R., Bonneau, F., 2013. Current bottlenecks in geomodeling workflows and ways forward. Bulletin of Canadian Petroleum Geology (Geomodeling Special issue - Gussow Conference).

Cherpeau, N., Caumon, G., Caers, J. K., Lévy, B., 2012 Method for stochastic inverse modeling of fault geometry and connectivity using flow data. Mathematical Geosciences 44 (2), 147-168.

Cherpeau, N., Caumon, G., Lévy, B., 2010a. Stochastic simulation of fault networks from 2D seismic lines. SEG Technical Program Expanded Abstracts 29 (1), 2366-2370.

Cherpeau, N., Caumon, G., Lévy, B., 2010b. Stochastic simulations of fault networks in 3D structural modeling. Comptes Rendus Geosciences 342 (9), 687 - 694.

Cowie, P. A., Shipton, Z. K., 1998. Fault tip displacement gradients and process zone dimensions. Journal of Structural Geology 20 (8), 983 - 997.

Dahlstrom, C., 1969. Balanced cross sections. Canadian Journal of Earth Sciences 6, 743,757.

Durand-Riard, P., Caumon, G., Muron, P., 2010. Balanced restoration of geological volumes with relaxed meshing constraints. Computers and Geosciences 36 (4), 441-452.

Egan, S., Kane, S., Buddin, T., Williams, G., Hodgetts, D. 1999. Computer modelling and visualisation of the structural deformation caused by movement along geological faults. Computers \&amp; Geosciences 25 (3), 283 - 297.

Fletcher, R., Pollard, D., 1999. Can we understand structural and tectonic processes and their products without appeal to a complete mechanics? Journal of structural geology 21 (8-9), 1071-1088.

Frank, T., Tertois, A., Mallet, J., 2007. 3D-reconstruction of complex geological interfaces from irregularly distributed and noisy point data. Computers and geosciences 33 (7), 932-943.

Georgsen, F., Røe, P., Syversveen, A. R., Lia, O., 2012. Fault displacement modelling using $3 \mathrm{D}$ vector fields. Computational Geosciences 16, 247-259.

Grasemann, B., Martel, S., Passchier, C., 2005. Reverse and normal drag along a fault. Journal of Structural Geology 27 (6), $999-1010$.

Grasemann, B., Stwe, K., Vannay, J.-C., 2003. Sense and non-sense of shear in flanking structures. Journal of Structural Geology 25 (1), $19-34$

Guillen, A., Calcagno, P., Courrioux, G., Joly, A., Ledru, P. 2008. Geological modelling from field data and geological knowledge: Part ii. modelling validation using gravity and magnetic data inversion. Physics of the Earth and Planetary Interiors 171 (1-4), 158 - 169, recent Advances in Computational Geodynamics: Theory, Numerics and Applications.

Hamblin, W., 1965. Origin of reverse drag on the downthrown side of normal faults. Geological Society of Amer- ica Bulletin 76 (10), 1145

Hjelle, Ø., Petersen, S., 2011. A hamilton-jacobi framework for modeling folds in structural geology. Mathematical Geosciences, 1-21.

Hobbs, B., Means, W., Williams, P., 1976. An outline of structural geology. Vol. 570. Wiley New York, NY.

Holden, L., Mostad, P., Nielsen, B., Gjerde, J., Townsend, C., Ottesen, S., 2003. Stochastic structural modeling. Mathematical geology 35 (8), 899-914.

Hollund, K., Mostad, P., Fredrik Nielsen, B., Holden, L., Gjerde, J., Grazia Contursi, M., McCann, A., Townsend, C., Sverdrup, E., 2002. Havana-a fault modeling tool. Norwegian Petroleum Society Special Publications 11, $157-171$

Jessell, M., Ailleres, L., de Kemp, E., 2010. Towards an integrated inversion of geoscientific data: What price of geology? Tectonophysics 490 (3-4), 294-306.

Jessell, M., Valenta, R., 1996. Structural geophysics: integrated structural and geophysical modelling. Computer Methods in the Geosciences 15, 303-324.

Kaven, J., Mazzeo, R., Pollard, D., 2009. Constraining surface interpolations using elastic plate bending solutions with applications to geologic folding. Mathematical Geosciences 41 (1), 1-14.

Kim, Y., Sanderson, D., 2005. The relationship between displacement and length of faults. Earth Science Reviews 68 (3-4), 317-334.

Maerten, L., Maerten, F., 2006. Chronologic modeling of faulted and fractured reservoirs using geomechanically based restoration: Technique and industry applications. AAPG bulletin 90 (8), 1201-1226.

Maerten, L., Willemse, E. J., Pollard, D. D., Rawnsley, K., 1999. Slip distributions on intersecting normal faults. Journal of Structural Geology 21 (3), 259 - 272.

Mallet, J.-L., 2002. Geomodeling. Oxford University Press, New York, NY, USA.

Mallet, J.-L., january 2004. Space-time mathematical framework for sedimentary geology. Mathematical Geology 36 (1), 1-32.

Means, W., 1989. Stretching faults. Geology 17 (10), 893896.

Moretti, I., Lepage, F., Guiton, M., 2006. Kine3D: A new $3 \mathrm{D}$ restoration method based on a mixed approach linking geometry and geomechanics. Oil \& Gas Science and Technology 61 (2), $277-289$.

Moyen, R., Mallet, J.-L., Frank, T., Leflon, B., Royer, J.J., 2004. 3D-parameterization of the 3D geological space the GeoChron model. In: Proc. European Conference on the Mathematics of Oil Recovery (ECMOR IX). A004, 8 p.

Reches, Z., Eidelman, A., 1995. Drag along faults. Tectonophysics 247 (1-4), 145-156.

Soliva, R., Benedicto, A., Schultz, R., Maerten, L., Micarelli, L., 2008. Displacement and interaction of normal fault segments branched at depth: Implications for fault growth and potential earthquake rupture size. Journal of Structural Geology 30 (10), 1288-1299.

Tanner, D. C., Behrmann, J. H., Dresmann, H., 2003. Threedimensional retro-deformation of the lechtal nappe, northern calcareous alps. Journal of Structural Geology 25 (5), $737-748$.

Theisel, H., Weinkauf, T., Hege, H., Seidel, H., 2005. Topological methods for $2 \mathrm{~d}$ time-dependent vector fields based on stream lines and path lines. IEEE Transactions on Visualization and Computer Graphics, 383-394. 
Thibaut, M., Gratier, J., Léger, M., Morvan, J., 1996. An inverse method for determining three-dimensional fault geometry with thread criterion: application to strike-slip and thrust faults (western alps and california). Journal of Structural Geology 18 (9), 1127-1138.

Thibert, B., Gratier, J., Morvan, J., 2005. A direct method for modeling and unfolding developable surfaces and its application to the ventura basin (california). Journal of structural geology 27 (2), 303-316.

Von Funck, W., Theisel, H., Seidel, H., 2006. Vector field based shape deformations. ACM Transactions on Graphics (TOG) 25 (3), 1118-1125.

Walsh, J., Nicol, A., Childs, C., 2002. An alternative model for the growth of faults. Journal of Structural Geology 24 (11), $1669-1675$.

Walsh, J., Watterson, J., 1987. Distributions of cumulative displacement and seismic slip on a single normal fault surface. Journal of Structural Geology 9 (8), 1039-1046.

Walsh, J. J., Bailey, W. R., Childs, C., Nicol, A., Bonson, C. G., 2003. Formation of segmented normal faults: a 3-d perspective. Journal of Structural Geology 25 (8), 12511262.

Walsh, J. J., Watterson, J., Bailey, W. R., Childs, C., 1999. Fault relays, bends and branch-lines. Journal of Structural Geology 21 (8-9), 1019 - 1026.

Yamada, Y., McClay, K., 2003. Application of geometric models to inverted listric fault systems in sandbox experiments. paper 1: 2d hanging wall deformation and section restoration. Journal of structural geology 25 (9), 15511560 . 